\title{
Summer Holidays
}

\section{Jacob Legge}

I went to the bluff with Jeremy. It was so cool, the sand was really hot and it's sooooo hard to climb on sand. We made a cave, you've gotta be careful though, cos they can collapse when you're in there and that's the worst way to die: buried in sand. At the top you can see for ages, and the lake is really flat even when it's choppy, cos you're so high, then you get sand all over you because we went in the swamp before, and it was all in my eyes, and the mud stinks in the swamp, but it's really cool to jump down the bluff, it's really scary, but you get braver, because you make bigger jumps, but I landed on a stick and it went into my foot, but it didn't hurt that much, but there was blood, but not too much because it all got covered in sand. Then I went for a swim and we went home. We left something in the cave, and closed it, I can't remember what it was, but we wanted to see if it would still be there later when we went back because it was hidden, 
and no one might find it. Jeremy went back, he said it was still there. He was sitting on my bed. It was hard to fit because the sides slide up like a cot. I'm not a baby, but it's good anyway because the floor is really hard and it would hurt if I fell.

Before, I had a whole room to myself, when they came to move me into the ward I wanted to wait for Mum, because I was on my own, and there was usually someone there, but the man said that Mum would still find me, but I knew that, I just wanted her to be there. I think the man thought I was a wuss, but I don't care.

We paddled to the bluff and it took ages, the water looks so cool when it's hot, it glints like a million sparkles. I guess it's a billion, or more or something, cos a million's not that much really. I got tired, but I'm pretty strong, so it was OK. I started on the surf ski, and he was on the windsurfer board but then we swapped, because the windsurfer is easier to paddle even though it's huge. Jeremy's older than me, so it was easier for him. He might have been stronger than me even when we were the same age, because he swims heaps.

My uncle Frank said that the first thing I said was, 'Can I have a drink, I'm dehydrated. He thought that was funny, because I was only eleven, and even he would have said thirsty, and he has a $\mathrm{PhD}$, which is pretty hard to get. Actually it wasn't the first thing I said; I swore a lot. Dad said he was shocked that I knew all those words, because I'm only eleven, and I didn't have a bed then because I wouldn't lie still, and I had a helmet on even though there were mattresses all over the floor. I had a splint on my arm, it wasn't broken, it was to stop me pulling the drip out, cos I couldn't eat. I wasn't unconscious then, cos I was screaming a lot, but not awake either. I don't remember that bit, but I didn't get in trouble for swearing. Someone told me 
everyone was happy when I said I was dehydrated because they knew the accident hadn't made me a different person. I think I am a bit different though, cos my arm doesn't move, and I can't walk.

Jeremy put pillows against the sides of the bed that slide up, and we watched a movie about a guy who got shrunk down in a tiny space ship and injected into another guy, and another one about some guys who made a beautiful woman from the computer. They were pretty funny. Wayne always says I'm lucky, cos I have all these beautiful nurses looking after me, but I don't care that much because they're way too old for me, but I don't say that cos I know he's joking. I'm glad they aren't my age, cos they have to take me to the toilet and the bath, and otherwise I would be embarrassed, and they would probably not be good nurses if they were only eleven. The bath is cool, it's on wheels, but they still have it in a different room so everyone can't see you in the bath, sometimes I worry that people can see my thing because I'm wearing short pyjamas and sometimes it falls out. Once I was eating peas, which are really hard to eat in bed, even though there's a cool table that comes out over the bed, I wish I could have one at home. I dropped a pea, and it went into my shorts, right next to my private parts, and I picked it up and put it back on my plate, then I didn't know which one it was cos peas all look the same, so I must have eaten it, cos I wanted to eat them cos I really like peas. Then I felt bad because that's disgusting, but I suppose it's funny too. I didn't tell anyone.

People say hospital food is bad, but I really like it, they have roast beef and fish fingers and other stuff, not all together though, they're different meals you can choose, cos they have a menu. Roast beef is harder though because I can't cut it on my own, cos my left hand 
doesn't move, I can't even feel it. You could stab it and I wouldn't know. But don't do that. We went camping at Bunga Arm, in the boat, which is really fun, cos we had a fire, and cut down trees. Just little ones though, but I still felt bad, cos I'm an environmentalist, but I like cutting down trees too. I kind of like the boat, it's cool to go fast, but it's scary too. Dad always drives too fast, and I feel like I'm going to fall out when the boat goes bang bang on the waves. Once my tooth hit the frame of the windscreen when we came down, and I broke my front tooth, cos my teeth stick out a bit. Dad made a joke about making a dint on the boat, but I think he did care more about my tooth, cos we got my tooth fixed, but not the boat. It's only a small dint anyway, you can hardly see it.

Christmas holidays are really long, and lots of people come down. My friend David was on the windsurfer when I got hit. I mean we both were, but he was at the back, so the boat missed him. Lucky, cos the day before we figured out that I had to go on the front, cos I'm much stronger than him, and I know how to paddle better. We went out when it was really windy, and we thought we wouldn't be able to get back, which was scary, even though Dad could always come and get us with the boat. It would have been bad if David got hit, cos he was the visitor. It's funny, cos his parents didn't want him to come down with us, and they had a big fight, but it was OK, cos he didn't get hurt. It was the best Christmas holidays ever cos it was so hot, and heaps of people came down, and apparently I went in an ambulance and then an aeroplane, and then a helicopter to get to the hospital. Mum made a joke that it was lucky that we had ambulance cover, cos that would have cost thousands, but she probably wouldn't have worried too much about the money, cos I got hurt really badly, and she was probably worried about that. 


\section{Summer Holidays}

I was scared to go in the ward at first, cos there were lots of people in there, and I feel a bit funny when there are lots of people around. I get lots of visitors which is really good, and I get heaps of presents, and Alex is jealous, but that's stupid because I don't really want to be in hospital. But I like it now in the ward because it's pretty funny. The doctor asked the boy in the bed opposite me and one to the right when was the last time he had a bowel movement, but the boy didn't understand so his Mum whispered 'when did you last have a poo', and the boy said 'this morning.' And he had a bike bell stuck in his head, which is pretty funny, or maybe it's not. But it is, cos he was alright, he didn't stay long. I always thought it was OK to leave the bell like that when the top falls off and the screw bit sticks out, cos it still makes a bit of a noise even if it doesn't ding properly. But I think you should fix it because you might fall and get it stuck in your head. There is another boy opposite now, he has a scar on his head, and no hair, he screams a lot which is annoying, cos it's hard to sleep at night, but it's not too bad, cos the nurses are really nice. And the girl in the bed next to me is nicer now. She used to scream too, and she told her mum to fuck off and said that she was a cunt, which is pretty rude but she didn't get in trouble, cos she got kicked in the head by a horse. And Jenny said it's a real shame cos she was really pretty before, but it would still be a shame if she wasn't.

Seems like lots of things are dangerous, but there's a girl in my row at the end, she's behind a curtain, cos she's older. Mum says she's amazing, cos she's always so positive, and she makes jokes and smiles even when she's going in for another operation, and I think she's going to die. But she didn't even have an accident, just a tumour in her head. I want to be careful now that I've had an accident, but 
I don't know how to be careful about tumours. The older girl used to scream a lot, but now she makes jokes, I can't really hear them, but they might be funny cos she looks nice even though some of her hair isn't there. My hair is half missing too, it's growing back, but it's longer on one side, cos they only shaved the right side where the dint is.

Dad says I should tell people that I got the scar in a knife fight in Brazil, but I just say I got hit by a boat. When I woke up there was a whiteboard that said I was in hospital, and I got hit by a boat, but I was safe now, and David and Susie and Beth and Tess and Jeremy were alright. I don't know why they said Suzie, cos she wasn't even at Loch Sport, but I was still glad she was alright. She's really nice, she peeled me a grape. Even though grapes are really nicer with the skin on, that was still a really nice thing to do. Dad took me for a walk in the park next to the hospital. I was in my wheel chair which is kind of fun, even though it's hard to use with one hand. We saw a helicopter land which was cool, but maybe it wasn't, cos they rushed inside with a stretcher, and it must have been another kid, cos it's the children's hospital. I haven't learned to walk yet, but Dad stood me up on my own for a bit and I didn't fall down which is good. My uncle Ray and auntie Jane who don't want to have kids came to visit, and they're really nice, cos they asked what present I wanted, and I said an elephant stuffed toy, cos I have a lion and a panther and a penguin and an orang-utan already, but it was too expensive, so they bought me a Porsche 959 which costs half a million dollars, but mine is just a toy which is better than an elephant anyway. Jane asked if she should stroke my head when I was going to sleep which is strange, and I went to sleep really quickly. 
I tried to make an island in the shallow part of the lake, and it was really hard, even though I used sticks and seaweed for reinforcement, it just washed away, and there wasn't even a bump under the water. Then I put the banana lounge in the shallow part and sat there in the sun on top of the water and relaxed. Then I went for a paddle with David, cos there were so many people to play with I didn't play with him enough, and I needed to look after him, cos he's a visitor. 